\title{
Ethical Standards of Scientific Research for Beginning Accounting Scholars
}

\author{
Cole J. Engel, MBA, CPA \\ Department of Economics, Finance, and Accounting, Fort Hays State University \\ 600 Park Street, Hays, KS 67601, United States
}

Tel: 1-785-628-5325_E-mail: cjengel2@fhsu.edu

Received: January 11, 2016 Accepted: January 25, 2016

doi:10.5296/ber.v6i1.8844 URL: http://dx.doi.org/10.5296/ber.v6i1.8844

\begin{abstract}
Analogous to public and private accounting practice, ethical scientific researchers must maintain the standards of honesty and objectivity as they carry out their scholarly pursuits. Any activities that compromise honesty and objectivity may introduce bias into research. Ethical considerations play a role in all research, and all investigators must be aware of and attend to the ethical considerations related to their studies. A foundation of trust is vital to scientific research. Nevertheless, ethical practice involves much more than merely following a set of guidelines. Ethical issues often have no easy answer. The issues are never black and white. Rather, they are various shades of grey. This article discusses how to ensure that all aspects of proposed research proceed with care and integrity and meet the ethical standards of scientific research.
\end{abstract}

Keywords: Ethical Standards, Scientific Research, Beginning Accounting Scholars, Research Bias

\section{Introduction}

The American Institute of Certified Public Accountants (AICPA) membership adopted its Code of Professional Conduct to provide guidance and rules to all members - those in public practice, in industry, in government, and in education - in the performance of their professional responsibilities. The profession recognizes its responsibilities to the public, to clients, and to colleagues. The AICPA Code of Professional Conduct calls for an unswerving commitment to honorable behavior, even at the sacrifice of personal advantage (AICPA, 2012). Analogous to public and private accounting practice, ethical scientific researchers must maintain the standards of honesty and objectivity as they carry out their scholarly 
pursuits. Any activities that compromise honesty and objectivity may introduce bias into research. These activities must be recognized and minimized immediately. If not, various stakeholder groups, from mentors and advisors to reviewers and future consumers of the project may end up as victims rather than benefactors of the study (CSEPP, 2009).

A distinct characteristic of a profession is its members' acceptance of their obligation to the public. The accounting profession's public consists of clients, lenders, governments, employers, investors, the business and financial community, industry groups, and all others who rely on the objectivity and integrity of certified public accountants to maintain the orderly function of commerce. In the practice of public accounting, certified public accountants also provide leadership in accounting research and education. Educational services (i.e., engaging in research and scholarship) are included in the definition of professional services for certified public accountants. Therefore, certified public accountants shall maintain objectivity and integrity, shall be free of conflicts of interest, and shall not knowingly misrepresent facts or subordinate his or her judgment to others as they pursue scholarly research (AICPA, 2012).

Ethical considerations play a role in all research, and all investigators must be aware of and attend to the ethical considerations related to their studies. A foundation of trust is vital to scientific research. To maintain society's trust, the results of research must reflect an investigator's work honestly and accurately. Fellow researchers rely on carefully gathered data, appropriate analytical and statistical techniques, accurate results, and respect for other investigators as they advance their fields of study (Committee on Science, Engineering, and Public Policy [CSEPP], 2009). Current ethical guidelines for behavioral research originated in The Belmont Report: Ethical Principles and Guidelines for the Protection of Human Subjects Research. The three basic ethical principles described in the report are respect for persons, beneficence, and justice (Office for Human Research Protections [OHRP], 1979).

The American Psychological Association (APA) also publishes ethical standards intended to provide guidance for psychologists and other researchers who adopt those standards. The APA Ethical Principles of Psychologists and Code of Conduct contains 10 headings, which are not limited to research. The 10 headings are: (a) Resolving Ethical Issues, (b) Competence, (c) Human Relations, (d) Privacy and Confidentiality, (e) Advertising and Other Public Statements, (f) Record Keeping and Fees, (g) Education and Training, (h) Research and Publication, (i) Assessment, and (j) Therapy (APA, 2010).

Nevertheless, ethical practice involves much more than merely following a set of guidelines. Ethical issues often have no easy answer. The issues are never black and white. Rather, they are various shades of grey. Proposal writers must consider ethical concerns as they design studies so they can build sound ethical practice into their designs. Codes of ethics provide guidance, but ethical conduct ultimately depends on individual researchers. Investigators must carefully administer the research process to ensure each step is following the highest standards of conduct possible (Burian, Rogerson, \& Maffei, 2010). This article discusses how to ensure that all aspects of proposed research proceed with care and integrity and meet the ethical standards of scientific research. 


\section{Institutional Review Boards}

Institutional Review Boards (IRBs) are federally mandated, locally administered groups charged with evaluating the risks and benefits of human participant research at their institutions. The ethical principles regarding research involving human subjects set forth in The Belmont Report guide the regulatory framework that surrounds all IRB action. IRBs exist to ensure that investigators follow ethical behaviors and procedures in research conducted on human subjects that are scientific, ethical, and regulatory in nature. Additionally, IRBs must approve or require modifications prior to beginning any research project (Burian et al., 2010).

The mission of a university's IRB is to protect the dignity, rights, and welfare of human participants in research conducted by students, faculty, and staff. When institutional approval is required, as it is at most institutions, students must provide accurate information regarding their research proposals (APA, 2010). The IRB must review and approve all research involving human subjects conducted by researchers before they undertake any investigation. Once approved, investigators must conduct their studies in accordance with the accepted research protocol (APA, 2010).

The IRB application typically requires the principal investigator to perform a risk assessment, which seeks to classify the proposed research study as exempt research, minimal risk research, or greater than minimal risk research. Risk assessments are necessary and vital for ensuring sound research projects. Researchers must acknowledge and identify risks and work to avoid them (Ranjbar, 2012). Risks in research include physical, psychological, social, or economic harms, the invasion of privacy, and violations of basic human rights. Researchers must perform safe and ethical research that minimizes risks to participants and maximizes benefits to their fields of study (OHRP, 1979). Prior to conducting a research project, the IRB will likely require the investigator to complete research ethics training, such as the Collaborative Institutional Training Initiative (CITI) online course.

\section{Informed Consent}

Conceivably, the most basic and important ethical issues in research are concerned with protection of participants. The principle of informed consent is fundamental to the conduct of ethical research. Researchers must obtain informed consent from participants before collecting data. Informed consent ascertains that participants partake in the study at their own free will and with a solid understanding of the nature of the study and any possible dangers that may arise because of participation. This requirement embraces research involving data collection using interviews, questionnaires, focus groups, and observation (Smith, 2011a). During informed consent procedures, researchers inform participants about the purpose of the project, their right to decline participation, and any foreseeable consequences of deciding to decline participation. Additionally, researchers inform participants about the research risks and benefits, limits to participant confidentiality, incentives to encourage participation, and contact information for the investigators conducting the study (APA, 2010).

One of the key ethical issues that researchers face when administering attitude or perception surveys is confidentiality for respondents (Smith, 2011b). The risk of loss of expected privacy 
and confidentiality is a concern; therefore, researchers must mitigate this concern by ensuring that the research instrument asks for no identifying information that could connect a participant's identity with the data. In addition, the survey system should disassociate e-mail addresses from submitted responses to maintain confidentiality. Researchers must be devoted to treating all respondents with dignity, reducing discomfort to absolute minimum levels, and protecting the confidentiality of survey data.

A second ethical concern relates to fairness. Survey questions should not lead participants toward certain answers or suggest that responses that are more positive will make the survey easier to complete. Leading questions create bias in the research study, which will make the study less valid (Smith, 2011b). To avoid bias, researchers should strive to use published instruments in which established validity and reliability of scores obtained from past use of the instrument already exists. In compliance with the principle of respect for persons, the survey system should allow subjects to withdraw from participation in the study without negative consequences. Should participants feel that bias is included in any question, they should have the opportunity to withdraw from the study.

\section{Reporting Results}

Researchers have a professional duty as academics to inform both student and practitioner audiences of the outcomes of current research and their implications for practice (Smith, 2011a). Therefore, researchers must not fabricate or falsify data. Additionally, if researchers discover errors in their data, they must take steps to correct such errors (APA, 2010). Researchers who fabricate or falsify data violate the basic values and professional standards of science. Misleading or inaccurate data from poor research design, careless measurements, or improper manipulation misleads other researchers and potentially impedes progress in the field of study. Researchers must be careful to choose appropriate statistical tests of significance, properly phrase survey questions, and carefully describe their studies so that other researchers can verify and possibly extend the results (CSEPP, 2009).

Investigators should choose research designs based on previously published peer-reviewed studies existing in the literature of the field under study. Studies should include a comprehensive description of the procedures used to produce the data. This will permit reviewers and readers to evaluate the validity of the data and the reliability of the employed methods. It is imperative that others can check and replicate a researcher's work if they are to verify and build on the study (CSEPP, 2009). Honest and transparent reporting of research is an ethical duty of scholars. Therefore, investigators should report everything they did, why they chose all courses of action, and how they conducted all procedures (Smith, 2011a).

All research is prone to error. Therefore, scholars must be as careful as possible. All researchers are human, and even the most responsible researcher can make an honest mistake. Research design, instrument calibration, data recording, and interpretation of the results are all susceptible to honest mistakes. Consequently, every study must be carefully prepared, submitted to the peer review process, and scrutinized. Should mistakes arise, researchers must correct them in a timely manner and in a way that maintains the integrity of the original study and prevents other researchers from extending the inaccurate results (CSEPP, 2009). 
It is imperative that all scholars recognize that negligent researchers place their own reputations, as well as the reputations of colleagues and the public's trust in science, at risk (CSEPP, 2009). Therefore, scholars must make every effort to exercise due care during the research process to ensure the integrity of their studies as well as the reputation and public confidence in their fields of study. Should a mistake arise, investigators should promptly notify their mentors and begin to take the necessary steps toward correcting any inaccurate results.

\section{Mentor Relationships}

Effective mentoring relationships between students and faculty are critical in facilitating the timely completion of research projects. Effective relationships are also important to the professional, cognitive, and emotional development of new scholars (Bell-Ellison \& Dedrick, 2008). The primary role of a mentor is to help a beginning scholar advance a productive and successful research project. However, the relationship between a mentor and beginning scholar can be complex. It is possible for conflicts to arise over the allocation of credit for the work completed, publication of the study, or the division of labor during the project. Because mentors have extensive influence over beginning scholars, they must be careful not to abuse their authority (CSEPP, 2009).

\section{Plagiarism}

Plagiarism is using someone else's work, intentionally or not, as one's own or for one's own benefit (Perry, 2010). It is imperative that scholars discuss and discourage this serious ethical issue in all contexts. Researchers must never represent another's work, or portions of another's work, as their own. Additionally, researchers must never publish work previously published unless accompanied by proper acknowledgement. Under no circumstances is it acceptable for previously published data to reappear as original work (APA, 2010). There is extensive evidence that suggests practicing scholars are plagiarizing for their own personal advancement. Understanding and preventing plagiarism in the academy is imperative because academics are responsible for mentoring and teaching beginning scholars. Academics are also responsible for publishing innovative scholarly contributions for the advancement of science and for upholding the highest ethical standards in society (Honig \& Bedi, 2012). Although tempting, it is unethical to adopt someone else's idea without giving appropriate credit to the originator. Scholars are obligated to give credit where credit is due so that other researches can locate the original source in their own efforts to extend a particular line of research (CSEPP, 2009). Not only is plagiarism unethical and immoral, it may also be illegal if the plagiarized material is copyright protected (Shahabuddin, 2009).

Literature on research misconduct suggests that plagiarism is on the rise. This pervasive and frustrating problem, often facilitated by the Internet, ranges from sloppy paraphrasing to intentional copying of another's work without appropriate citation (Honig \& Bedi, 2012). This is profoundly damaging because it devalues academic degrees and demotivates honest students. Plagiarism, whether intentional or not, is simply unacceptable (Perry, 2010). Supported by theory and research evidence, Honig and Bedi (2012) asserted that academicians plagiarize because of pressure by their institutions to publish research. 
Unfortunately, the pressure of publishing in academia continues to increase because of ties to hiring, promotion, and funding. Authoring published research is vital to a professor's survival and success in the academy (Lazaroiu, 2012). The extent and quality of research is a major player in evaluating performance at universities (Northcott \& Linacre, 2010). The publish or perish ideology is at the root of the temptation for both students and mentors to plagiarize. This is especially true in self-plagiarizing situations where authors submit a similar publication to a different research outlet as original work. Increased pressure on professors provides temptations for wrongdoing in research and publishing (Lundin, 2011).

Regardless of intense pressure, there is no justification for plagiarizing. It simply sets a bad example for students and society and both academic and professional communities must not tolerate such behavior. It is imperative that the academy recognizes its role as educators of society's children. This role requires high ethical, moral, and legal standards to protect students, the public, and society as a whole. Failing in this regard will have devastating consequences for the future well-being of the world. Ignoring plagiarism suggests that researchers disregard unethical behavior. This will only encourage future plagiarism and possibly other unethical behaviors, such as falsifying or misrepresenting data. Like most ethical issues, plagiarism has no simple solution. Rather, it requires that scholars make a commitment to the highest ethical conduct in their disciplines. This includes the misuse of a fellow researcher's words and ideas (Shahabuddin, 2009).

\section{Conclusion}

This article discussed how to ensure that all aspects of proposed research proceed with care and integrity and meet the ethical standards of scientific research. Ethical scientific researchers have a commitment to all who are touched by their research (e.g., participants who share their lives and time, mentors and advisors, reviewers, future readers, and supporters and cheerleaders on the journey) to take care and do their work well. Ethical scientific researchers must maintain the standards of honesty and objectivity as they carry out their scholarly pursuits. Any activities that compromise honesty and objectivity may introduce bias into research. These activities must be recognized and minimized immediately. If not, various stakeholder groups, from mentors and advisors to reviewers and future consumers of the project may end up as victims rather than benefactors.

\section{References}

American Institute of Certified Public Accountants [AICPA]. (2012). Code of Professional Conduct and Bylaws. Retrieved from http://www.aicpa.org/Research/Standards/CodeofConduct/Pages/default.aspx

American Psychological Association [APA]. (2010). Ethical principles of psychologists and code of conduct (Standard 8: Research and Publication). Retrieved from http://www.apa.org/ethics/code/index.aspx

Bell-Ellison, B. A., \& Dedrick, R. F. (2008). What do doctoral students value in their ideal mentor? Research in Higher Education, 49(6), 555-567. http://dx.doi.org/10.1007/s11162-008-9085-8 


\section{MInstitute Macrothink $_{\text {Int }}$}

Business and Economic Research

ISSN 2162-4860

2016, Vol. 6, No. 1

Burian, P. E., Rogerson, L., \& Maffei, F. R. (2010). The research roadmap: A primer to the approach and process. Contemporary Issues in Education Research, 3(8), 43-57. Retrieved from http://journals.cluteonline.com/index.php/CIER

Committee on Science, Engineering, and Public Policy [CSEPP], National Academy of Sciences, National Academy of Engineering, \& Institute of Medicine. (2009). On being a scientist: A guide to responsible conduct in research (3rd ed.). Retrieved from National Academies Press website http://www.nap.edu/catalog.php?record_id=12192

Honig, B., \& Bedi, A. (2012). The fox in the hen house: A critical examination of plagiarism among members of the academy of management. Academy of Management Learning \& Education, 11(1), 101-123. http://dx.doi.org/10.5465/amle.2010.0084

Lazaroiu, G. (2012). The pressure of publishing in academia. Economics, Management and Financial Markets, 7(1), 120-125. Retrieved from http://addletonacademicpublishers.com /economics-management-and-financial-markets/journals/emfm/about-the-journal.html

Lundin, R. A. (2011). Ethical considerations in doing and disseminating project management research. International Journal of Managing Projects in Business, 4(1), 150-156. http://dx.doi.org/10.1108/17538371111096944

Northcott, D., \& Linacre, S. (2010). Producing spaces for academic discourse: The impact of research assessment exercises and journal quality rankings. Australian Accounting Review, 20(1), 38-54. http://dx.doi.org/10.1111/j.1835-2561.2010.00079.x

Office for Human Research Protections [OHRP]. (1979). The Belmont Report: Ethical principles and guidelines for the protection of human subjects of research. Retrieved from http://www.hhs.gov/ohrp/humansubjects/guidance/belmont.html

Perry, B. (2010). Exploring academic misconduct: Some insights into student behaviour. Active Learning in Higher Education, 11(2), 97-108. http://dx.doi.org/10.1177/1469787410365657

Ranjbar, V. (2012). Risk assessment as a paradox: When actions of an IRB become incompatible with ethical principles. Accountability in Research: Policies and Quality Assurance, 19(5), 273-284. http://dx.doi.org/10.1080/08989621.2012.718678

Shahabuddin, S. (2009). Plagiarism in academia. International Journal of Teaching and Learning in Higher Education, 21(3), 353-359. Retrieved from http://www.eric.ed.gov/contentdelivery/servlet/ERICServlet?accno=EJ909069

Smith, M. (2011a). Research ethics in accounting. In Research methods in accounting (2nd ed., pp. 93-100). Thousand Oaks, CA: Sage.

Smith, M. (2011b). Survey research. In Research methods in accounting (2nd ed., pp. 116-131). Thousand Oaks, CA: Sage. 


\section{Copyright Disclaimer}

Copyright for this article is retained by the author(s), with first publication rights granted to the journal.

This is an open-access article distributed under the terms and conditions of the Creative Commons Attribution license (http://creativecommons.org/licenses/by/3.0/). 